\title{
A RESPONSABILIDADE DE EMPRESAS TRANSNACIONAIS POR VIOLAÇÃO DE DIREITOS HUMANOS: Estudo de Caso Sobre o Trabalho em Condições Análogas ao de Escravo na Indústria Têxtil
}

\author{
Leticia Alves de Jesus \\ Autora correspondente. Pontifícia Universidade Católica do Paraná. Rua Imaculada Conceição, 1155 - Prado Velho. Curitiba/PR, \\ Brasil. CEP 80215-901. http://lattes.cnpq.br/0736009944701705. https://orcid.org/0000-0003-3228-4805. \\ leticia.alves.doc@gmail.com \\ Luís Alexandre Carta Winter \\ Pontifícia Universidade Católica do Paraná. Curitiba/PR, Brasil.
}

Em decorrência da ascensão da riqueza e poder econômico das grandes corporações, que passaram a figurar como novos atores na comunidade internacional, há a necessidade que o Direito assegure que as relações decorrentes desta perspectiva sejam regulamentadas conforme os preceitos difundidos na comunidade internacional. Um dos principais obstáculos enfrentados nesta perspectiva é o controle e repressão de atos de violação aos direitos humanos praticados por empresas transnacionais. Com intuito de analisar esta temática o presente trabalho visa a responder à seguinte questão: Quais os meios existentes para minorar e/ou eliminar as violações de direitos humanos pelo setor da indústria têxtil transnacional? Para isso foi necessário estudar e analisar instrumentos legais efetivos de controle nacional e internacional das ações desses novos atores, de forma que os atos de violação de direitos humanos perpetrados por estas empresas sejam prevenidos e reparados de forma adequada. Com o objetivo de realizar este estudo foi utilizado o método hipotético-dedutivo, tendo-se selecionado o setor da indústria têxtil como forma de tornar mais precisa a análise dos instrumentos de controle existentes.

Palavras-chave: responsabilidade de empresas; direitos humanos; proteção nacional; proteção internacional; trabalho análogo ao escravo.

THE RESPONSIBILITY OF TRANSNATIONAL CORPORATIONS FOR HUMAN RIGHTS VIOLATION: CASE STUDY ON WORK IN SIMILAR CONDITIONS TO SLAVERY IN THE TEXTILE INDUSTRY

As a result of the rise of wealth and economic power of large corporations, which have come to represent as new actors in the international community, there is a need for the law to ensure that the relations arising from this perspective are regulated according to the precepts disseminated in the international community. One of the main obstacles faced in this perspective is the control and repression of acts of human rights violations practiced by transnational corporations, and the purpose of this article is to analyze this problem. In order to answer the following question: what means exist to reduce and / or eliminate human rights violations by the transnational textile industry, it was necessary to study and analyze effective legal instruments for national and international control of the actions of these new actors, so that the acts of human rights violations perpetrated by these companies are adequately prevented and remedied. In order to perform this study, the hypothetical-deductive method was used, and the textile industry was selected as a way of making the analysis of the existing control instruments more accurate.

Keywords: corporate responsibility; human rights; national protection; international protection; work analogous to the slave. 


\section{INTRODUÇÃO}

Este artigo teve como objetivo investigar instrumentos nacionais e internacionais de repreensão de atos de violação de direitos humanos praticados por empresas transnacionais. Com esse objetivo foi selecionada especificamente a análise de casos práticos envolvendo a exploração do trabalho análogo ao de escravo na indústria têxtil, com intuito de estudar a efetividade dos meios de responsabilização corporativa já existente, apontando as suas eventuais falhas, de forma a intensificar a discussão sobre esse tema e abrir a possibilidade de criação de métodos mais eficientes de responsabilização de empresas transnacionais.

A temática foi selecionada em decorrência do papel fundamental das grandes corporações no panorama internacional atual. Deste modo é imprescindível que se estabeleçam diretrizes estáveis e efetivas para a responsabilização de empresas transnacionais, principalmente no caso de transgressão aos direitos humanos.

Para esta análise foram selecionados dois casos importantes envolvendo a responsabilização de empresas do setor têxtil por atos de transgressão a direitos humanos: o caso envolvendo a empresa Zara Brasil e o caso contra M. Officer, que foram acusadas especificamente pela exploração de trabalho análogo ao de escravo.

O método utilizado para obter os resultados foi o procedimento de pesquisa bibliográfica, fazendo a análise desse tema por meio de materiais já publicados, usando do método hipotético-dedutivo com intuito de gerar conhecimento para aplicações práticas direcionadas à solução do problema.

Desta forma foi averiguada a efetividade dos instrumentos nacionais de proteção e prevenção utilizados nos casos sob análise, de modo a examinar a efetividade da repreensão de violação aos direitos humanos por empresas, também verificando a complementaridade dos mecanismos de proteção nos âmbitos internacional e nacional.

Com este objetivo o artigo foi dividido em três partes: a primeira tem como objetivo expor o tema da possibilidade de responsabilização de empresas transnacionais por violação aos direitos humanos e a construção desse conceito.

A segunda parte trata sobre os mecanismos existentes para a responsabilização de empresas por atos de violação de direitos humanos, analisando a sua efetividade dentro do meio internacional e nacional.

Já a última parte do artigo foi voltada para a análise específica dos instrumentos nacionais de responsabilização de empresas transnacionais por violação de direitos humanos, usando como base casos do Brasil no combate à violação de direitos humanos na indústria têxtil, como o caso Zara e M. Officer.

Ao final foi exposta a conclusão sobra a efetividade dos instrumentos de responsabilização de empresas transnacionais existentes com base nos exemplos expostos e nos trabalhos analisados, com intuito de reconhecer o meio mais adequado para que se obtenha efetividade no controle de atos ilícitos praticados por estas empresas. 


\section{RESPONSABILIDADE DE EMPRESAS TRANSNACIONAIS POR VIOLAÇÃO DE DIREITOS HUMANOS}

Para iniciar o estudo deste tema é necessário definir dois conceitos fundamentais para o desenvolvimento do artigo: a delimitação do que se entende por direitos humanos e o reconhecimento da responsabilidade de empresas transnacionais por transgressões de direitos. Esses conceitos são essenciais para que haja uma melhor compreensão dos instrumentos nacionais e internacionais de responsabilização dessas empresas, motivo pelo qual passaremos a expor de forma sucinta estes temas.

\subsection{Direitos Humanos e a Perspectiva dos Direitos Fundamentais}

Para uma análise precisa sobre os instrumentos de responsabilidade de empresas por violação a direitos humanos é inevitável inicialmente abordar a definição de direitos humanos. Assim, para os fins deste estudo deve-se entender os direitos humanos como "os direitos de que todos os homens são titulares pela suficiente condição de serem humanos, independente de qualquer outra condição ou circunstância" (COMPARATO, 1998, p. 74).

Para que se torne possível uma análise mais precisa desse tema dentro dos instrumentos nacionais de proteção a estes direitos, também é importante ressaltar que passaremos a tratar neste artigo dos direitos humanos e também dos direitos fundamentais; portanto, como o fim deste trabalho está na análise da eficácia dos instrumentos internacionais e nacionais de responsabilidade de empresas transnacionais, também será feito um estudo específico da responsabilização dessas empresas por transgressão a direitos fundamentais, na condição de direitos humanos positivados na Constituição Nacional.

Assim, como direito fundamental deve-se entender, para a análise deste artigo, os direitos humanos positivados na Constituição Nacional, conforme exposto no livro Liberdade e Direitos Humanos (BRITO, 2013), e também de acordo com o que leciona Canotilho, segundo o qual os direitos fundamentais são a positivação, por meio da constituição dos direitos humanos que, segundo o autor, são direitos naturais e imutáveis. Nesses termos:

Os direitos fundamentais serão estudados enquanto direitos jurídicos positivamente vigentes numa ordem constitucional. (...) A positivação de direitos fundamentais significa a incorporação na ordem jurídica positiva dos direitos considerados "naturais" e "inalienáveis" do indivíduo (CANOTILHO, 2002, p. 391).

Posto isso, no âmbito de proteção internacional dos direitos humanos um importante instrumento a ser tomado como base é a Declaração Universal dos Direitos Humanos (DUDH) de 1948, que estabelece objetivos comuns à comunidade internacional para a tutela do ser humano, e, apesar de a princípio a DUDH ser um instrumento que vincularia apenas os Estados no âmbito internacional, como previsto no próprio preâmbulo da declaração que menciona que os "Estados Membros se comprometem a promover, em cooperação com as Nações Unidas, o respeito universal aos direitos e liberdades fundamentais do homem e a observância desses direitos e liberdades" (ONU, 1948, p. 3), a transformação do cenário internacional e o crescente poder das empresas também tornaram necessário o reconhecimento da eficácia horizontal dos direitos humanos para se abrir a possibilidade de responsabilização de entes 
não estatais pela violação desses direitos, estando essa discussão em evolução, como se demonstrará detalhadamente no próximo ponto.

Uma vez definidos estes conceitos é necessário prosseguir para a exposição da possibilidade do reconhecimento da responsabilidade de empresas transnacionais por violação destes direitos.

\subsection{Atual Perspectiva da Responsabilidade de Empresas Transnacionais por Violação de Direitos Humanos}

A ascensão do poder e influência de empresas no cenário internacional torna imprescindível a necessidade de regulamentar as relações decorrentes dessa nova perspectiva conforme preceitos difundidos na sociedade internacional.

Para compreender o poder das grandes corporações no cenário atual, das 100 maiores economias do mundo 69 são empresas e não Estados, de acordo com o estudo feito pela Global Justice Now (2018), e, segundo Adam Winkler, autor no livro We the Corporation: how american bussines won their civil rights (2018), nos Estados Unidos as empresas americanas conquistaram direitos quase equivalentes aos atribuídos a cidadãos, como no caso Burwell vs Hobby Lobby Stores Inc.(2014), julgado pela Suprema Corte americana, que concedeu à empresa o direito de ter liberdade de expressão e liberdade religiosa.

Assim, com o crescente poder supranacional das grandes corporações é necessário que sejam estudados e definidos instrumentos legais de controle internacional e nacional efetivo das ações perpetradas por estes novos atores, de forma que os atos de violação de direitos humanos internacionalmente reconhecidos praticados por essas empresas sejam prevenidos e reparados de forma adequada.

Devido a essa perspectiva a Organização das Nações Unidas tem tomado diversas medidas para legitimar a horizontalidade dos direitos humanos, estendendo os deveres decorrentes deles a atores não estatais, como as corporações (KNOX, 2008).

Desde 1999 foram tomadas diversas ações pela ONU para promover o debate sobre esse assunto, a exemplo da criação em 2003 da subcomissão das "Normas sobre Responsabilidades das Empresas Transnacionais e outros Empreendimentos Comerciais em Relação aos Direitos Humanos", a qual reconheceu de forma expressa que empresas têm o "dever de respeitar e promover os direitos humanos (...) reconhecidos pelo direito internacional e pelas legislações nacionais" (ZANITELLI, 2011, p. 3).

Como um dos marcos mais importantes e recentes para a responsabilização de empresas transnacionais por violação a direitos humanos está a criação dos princípios orientadores "proteger, respeitar e reparar" (UNITED NATIONS, 2008), de John Ruggie em 2008, como Representante Especial do Secretário-Geral das Nações Unidas, tendo sido aprovado em junho de 2011 pelo Conselho de Direitos Humanos da ONU.

Estes princípios orientadores estão pautados em três principais partes:

(i) Estados possuem o dever de proteger contra violações de direitos humanos cometidas por terceiros, incluindo empresas, por meio de políticas, normas, bem como processos judiciais adequados; (ii) empresas possuem a responsabilidade de respeitar normas de direitos humanos, controlando os riscos de causar danos aos direitos humanos, buscan- 
do, em última instância, evitar tais danos; e (iii) vítimas de direitos humanos devem ter maior acesso a remédios efetivos, incluindo mecanismos não judiciais de denúncia (LESSA, 2017, p. 265).

Em decorrência, portanto, dos esforços promovidos pela ONU nos últimos anos já há uma base adequada para que se assegure a possibilidade da existência da responsabilidade de empresas transnacionais por transgressão a direitos humanos.

Assim, a partir desses mecanismos foram imputados aos Estados os deveres de prevenção, investigação, punição e reparação de violações a direitos humanos ocorridos no território sob sua jurisdição, e "recomendou-se a adoção de medidas com o intuito de prevenir violações cometidas além de seus limites territoriais por corporações neles domiciliadas" (LESSA, 2015, p. 102).

Desse modo, uma vez delimitado o conceito de direitos humanos, de direitos fundamentais e a atual perspectiva da responsabilidade de empresas transnacionais por violação de direitos humanos, é possível prosseguir com a análise detalhando as normas existentes de responsabilização destas.

\section{MECANISMOS EXISTENTES DE RESPONSABILIZAÇÃO DE EMPRESAS TRANSNACIONAIS POR TRANSGRESSÃO AOS DIREITOS HUMANOS E SUA EFETIVIDADE}

A partir do exposto é admissível concluir que há cada vez mais esforços para que se alcance o objetivo de efetivar instrumentos e meios eficientes de coibir e, eventualmente, punir práticas de violação de direitos humanos cometidos por empresas.

Um dos grandes problemas para a instituição de ferramentas efetivas que permitam a punibilidade de empresas transnacionais por atos de violação de direitos humanos está no caráter supranacional dessas empresas, que muitas vezes não são atingidas de modo eficiente pelas ferramentas nacionais existentes de repreensão dessas práticas.

Para evitar a impunidade destas empresas a ONU vem trabalhando continuamente para que "organizações internacionais e regionais elaborem políticas e instrumentos pertinentes (...) quanto à necessidade de aplicar sanções para atores não estatais transgressores de direitos humanos" (LESSA, 2017, p. 267), pois reconhece que em alguns casos a ação meramente estatal não é eficaz para efetuar a punibilidade de empresas transnacionais. Apesar, contudo, dos esforços e da evolução sobre a aplicabilidade desse tema "as obrigações de sujeitos não estatais permanecem inaptas a se fazerem valer internacionalmente em juízo contra esses mesmos sujeitos" (LESSA, 2017, p. 268).

Assim, enquanto organismos internacionais não possuem efetividade na punição das empresas transnacionais por violação a direitos humanos, cabe aos Estados o controle e a punição efetiva dessas práticas.

Como afirma Zanitelli:

Em outras palavras, embora se afirme o dever de respeito aos direitos humanos pelas companhias para além da mera observância às leis locais (United Nations, 2011, annex, para. 11), são os Estados, no exercício de suas respectivas jurisdições, os encarregados 
de investigar e punir o ocasional descumprimento, pelos empresários, de suas obrigações acerca dos direitos humanos (United Nations, 2011, annex, para. 25) (ZANITELLI, 2011, p. 40).

Desta forma esse cenário passa a ser um reflexo da natureza desses chamados "princípios-guia" criados pela ONU sobre empresas e direitos humanos, que possuem apenas um caráter de orientação, não tendo assim uma vertente legal impositiva.

Outro empecilho para que ocorra uma efetiva punibilidade internacional dessas práticas está no fato de as Cortes Internacionais se limitaram à punição de Estados, como refere-se o artigo 48 (I) (a) da Convenção Americana de Direitos Humanos de 1969; os artigos 33 e 34 do Conselho da Europa de 1950 e o artigo 47 da União Africana de 1981, tendo como única exceção de punibilidade efetiva de indivíduos por violação de direitos humanos o Tribunal Penal Internacional de acordo com o artigo 25 do Estatuto de Roma, mas este também encontra dificuldades ao atuar na punibilidade de casos envolvendo empresas, uma vez que só pode punir pessoas físicas.

Assim, a consequente dificuldade para a punibilidade internacional de empresas por transgressões a direitos, acaba por fazer com que esta dependa "(...) das legislações nacionais e também do alcance que se dê às jurisdições nacionais para fazer frente a abusos ocorridos além dos limites territoriais de cada país" (ZANTINELLI, 2011, p. 41).

Quanto a esse assunto há o marcante exemplo dos Estados Unidos no julgamento de casos com base no Alien Tort Claims Act, que tem "pleiteado reparação por ofensas a direitos humanos verificadas fora do território norte-americano por ou em cumplicidade com corporações norte-americanas ou suas subsidiárias" (JOSEPH, 2004, p. 21), constituindo esta uma forma de efetivar a punibilidade de empresas multinacionais.

O problema, entretanto, de deixar a cargo somente das jurisdições estatais a punibilidade de empresas transnacionais por violações a direitos humanos está no fato de que há uma dificuldade, principalmente para países subdesenvolvidos e em desenvolvimento, em tornar efetivo o estabelecimento de normas capazes de controlar e repreender atividades de empresas transnacionais em seu território, sendo essa dificuldade evidenciada pela cada vez maior força das empresas no cenário mundial, tendo inclusive algumas companhias mais poder econômico do que os próprios países em que estão instaladas, conforme mencionado anteriormente.

Como afirma Evaristus Oshionebo em seu artigo The U.N. global compact and accountability of transnational corporations: separating myth from realities (2007, p. 4):

Existe, entretanto, o receio de que as sanções instituídas pelos sistemas jurídicos nacionais sejam insuficientes para evitar violações. Salienta-se o fato de os países mais pobres, precisamente aqueles nos quais o risco de abusos é maior, são geralmente menos propensos a estabelecer normas capazes de inibir a atividade de grandes companhias em seus territórios.

Assim, pelo fato de os princípios instituídos internacionalmente não terem força sancionatória e pela falha da efetividade de muitas medidas estatais, há "um clamor para que as corporações se sujeitem internacionalmente a sanções por atos de desrespeito aos direitos humanos imputáveis a si ou às suas filiadas" (ZANITELLI, 2011, p. 41). Não há, contudo, um 
consenso sobre tal apelo, sendo questionada a capacidade de efetividade que a aplicação de sanções no meio internacional teria sobre a repreensão de ações ilícitas perpetradas por empresas transnacionais.

Há uma forte vertente doutrinária que entende não ser a melhor alternativa o apelo àprática de sanções internacionalmente aplicáveis, por entenderem que, em suma, as empresas se comportariam de modo que:

O respeito aos direitos humanos atende, em alguma medida, ao objetivo da maximização do lucro, esperando-se, assim, que as companhias evitem violações a esses direitos em seu interesse mesmo ou, em outras palavras, no interesse egoísta de seus acionistas (KELL, 2005, p. 376).

Desse modo, há estudos que revelam que a busca de ações sociais por empresas traz um desempenho financeiro positivo a estas companhias (MARGOLIS; ELFENBEIN; WALSH, 2007). Assim, a partir desses estudos e dessa vertente há evidências de que a busca de imposições de sanções internacionais mostrar-se-ia menos efetiva para a repreensão de práticas de transgressão a direitos humanos do que a efetivação de projetos para a promoção espontânea de proteção aos direitos humanos.

Ademais, essa corrente doutrinária também é defendida pelo fato de que há uma evidente dificuldade de submeter empresas transnacionais a normas vinculantes internacionais e a chegar a um consenso entre os Estados sobre essa questão para que se possa de fato impor sanções internacionais, como é exposto em diversos trabalhos (KELL, 2005, p. 74; RUGGIE, 2001, p. 373; ZANITELLI, 2011, p. 43). Assim, essa dificuldade encontrada para a adoção de normas sancionatórias internacionais para empresas transnacionais transgressoras de direitos humanos e o comprovado benefício financeiro que pode ser extraído pelas próprias companhias ao agirem de acordo com os preceitos de respeito aos direitos humanos faz com que muitos percebam que a melhor alternativa para solucionar esse problema seria investir em práticas de soft law como vem sendo tomadas pela ONU, por exemplo.

De acordo com o que expõe Zanitelli (2011, p. 43):

Soluções como o Pacto Global, baseadas no diálogo e na persuasão, seriam, segundo se pondera aí, quiçá não as melhores, mas, nas presentes circunstâncias, as únicas viáveis para a promoção dos direitos humanos no âmbito empresarial.

Ademais, outra vantagem na aplicação de normas de soft law como os princípios orientadores "proteger, respeitar e reparar" estaria no fato da sua maleabilidade, o que permitiria acompanhar de modo mais adequado e rápido as mudanças constantes do mercado empresarial e dos meios de produção. Como é mencionado por John Ruggie (2001), medidas de soft law destinadas a promover a aplicação gradativa de princípios de responsabilidade social às empresas são as que convêm, pela maleabilidade das suas disposições, ao estágio incipiente da doutrina jurídica acerca do conteúdo das obrigações atribuídas às corporações e também à grande velocidade com que se modificam as circunstâncias de produção, a exigir, tais modificações, uma frequente reelaboração das pautas de comportamento empresarial no que se refere ao respeito aos direitos humanos.

Nesse contexto, haveria também uma vantagem clara na aplicabilidade destas medidas em contraponto a medidas sancionatórias que teriam dificuldade de se adaptar às rápidas 
transformações do mercado empresarial, por terem de possuir uma melhor precisão e detaIhamento para a sua aplicação, o que poderia até levar a sua ineficácia.

A partir dessa vertente, todavia, não se deve concluir que uma normatização associada com sanções não seria eficiente, e muito menos que não deva ser buscada. Assim, deve-se ver a partir do ponto de que o objetivo seria a busca desta abordagem com o complemento de hard law em casos em que as prerrogativas de soft law não se mostrem suficientes.

Para os defensores da aplicação de sanções internacionais para repreender as práticas ilícitas atinentes à violação de direitos humanos por parte de empresas transnacionais o investimento em soft law não é eficiente ou, ao menos, não tem demonstrado eficácia para atingir um nível adequado de proteção aos direitos humanos, e para chegar a essa conclusão tomam como exemplo os próprios princípios orientadores criados pela ONU, que seriam ineficazes, sob a análise dessa corrente doutrinária, devido ao baixo número de corporações participantes e também pelo fato de que a adequação aos princípios pelas empresas participantes ser mínima e muitas vezes inclusive inadequada.

Por exemplo, segundo relatórios na ONU há atualmente 7.371 empresas que ratificaram o Pacto Global (2018) e 1.103 participantes, contudo dessas empresas 1.432 estão inativas, por não enviarem o relatório requerido atualmente sobre o cumprimento dos princípios e da prática de ações para efetivar os 10 princípios elencados no pacto, e dessas somente 25 empresas têm iniciativas efetivas relatadas para promover os direitos humanos e o trabalho adequado, o que demonstraria a pouca efetividade real das ações promovidas por organizações internacionais mediante normas de soft law para a repreensão das atividades de transgressão de direitos humanos praticadas por empresas.

É importante mencionar, contudo, que os favoráveis a esse posicionamento muitas vezes falham ao não apresentar o motivo pelo qual normas de soft law não seriam adequadas. De acordo com Zanitelli (2011, p. 45):

Embora costumem ressaltar a ineficácia do Pacto Global, seus opositores raramente explicitam as razões pelas quais o Pacto estaria, a exemplo de outras medidas voluntaristas, fadado ao fracasso. Essa descrença pode ser motivada por uma suposição que, de tão banal, não se julgue sequer merecedora de menção.

A questão então deve ser analisada a partir dos fins esperados com a vertente obrigacional para verificar qual a abordagem mais adequada para atingir os resultados pretendidos. Assim, passamos a analisar de forma resumida quais seriam os resultados obtidos com uma eventual imposição de sanção no âmbito internacional para empresas violadoras de direitos humanos.

\section{ANÁLISE DA EFETIVIDADE DE APLICAÇÃO DE SANÇÃO NO ÂMBITO INTERNACIONAL}

Um dos argumentos utilizados por aqueles que defendem a aplicação de sanções internacionais nesses casos parte da premissa de que quanto mais severa e precisa a pena, maior seria o controle sobre a ação ilícita e, portanto, menor seria a incidência deste ato. Esse entendimento está baseado em estudos econômicos como o feito por Becker (1968, p. 176), que a partir da análise econômica do crime e da sanção chegou ao seguinte resultado: 


\begin{abstract}
Afirma-se, assim, que em uma conduta ilícita é de se prever sempre que o seu benefício (ou "utilidade") esperado seja superior ao custo, o qual compreende o custo da conduta mesma para o agente mais o custo esperado da sanção. Esse custo esperado, por sua vez, é determinado pela gravidade da sanção (isto é, a sua "desutilidade" para o agente) e pela probabilidade (tal como percebida pelo potencial ofensor) de que ela seja imposta.
\end{abstract}

Isso posto, a criação de uma sanção para esses atos em âmbito internacional se justificaria pelo fato de que essa imposição reduziria a incidência da violação de direitos humanos por empresas, à medida que seria mais eficaz e precisa que os mecanismos aplicados pelos Estados isoladamente, como é feito atualmente.

Há, contudo, um grande perigo em aplicar essa lógica, uma vez que como demonstrado, há uma cada vez maior propensão das empresas em estabelecerem de forma autônoma normas de responsabilidade social, e deste modo a imposição de normas sancionadoras no âmbito internacional mostrar-se-ia desnecessária e até mesmo poderia levar à inibição desse comportamento. Como já demonstrado em vários estudos (FEHR, 2002; FISCHBACHER, 2004; ZANITELLI, 2011), o estabelecimento de normas legais punitivas acaba por enfraquecer a regra social que estabeleceu a razão pela qual a sanção foi imposta. Como expõe Zanitelli (2011, p. 48):

A crescente dedicação das empresas a fins socialmente valiosos é testemunhada não apenas anedoticamente - por exemplo, pelo número de corporações da lista das quinhentas maiores publicada pela Revista Fortune que fazem menção à responsabilidade social em seus relatórios anuais (Lee, 2008, p. 54) - mas também em estudos empíricos nos quais se empregam diferentes medidores, como contribuições de caridade, impacto ambiental e aplicação de sanções pela via administrativa ou judicial (MARGOLIS; ELFENBEIN; WALSH, 2007, p. 11-13).

Ademais, como é exposto na teoria do ponto focal do direito expressivo, local point theory of expressive law (GALBIATI; SCHLAG; VAN DER WEELE, 2009), as leis expressam valores sociais e têm como intuito moldar o comportamento individual, ou seja, para essa teoria a lei seria um ponto focal das disposições sociais já expostas na sociedade, e, de acordo Cooter (1998, p. 595), "A teoria expressiva do direito sustenta que provocar a obediência voluntária da maioria dos cidadãos torna a lei eficaz, e os efeitos podem ser maiores do que aplicar sanções estatais a alguns infratores", ou seja, a ideia central exposta nesses estudos é que a lei não precisa necessariamente ser severa para que tenha efetividade, ela pode ser branda e ter melhores resultados que uma lei mais rigorosa, pois o objetivo desta é criar um "ponto focal" dos comportamentos sociais.

Assim, de acordo com o exposto, no âmbito internacional de proteção aos direitos humanos o estabelecimento de soft law seria o modo mais adequado para assegurar que empresas atuem de acordo com o respeito a esses direitos, entretanto ainda é necessário analisar a efetividade dos mecanismos utilizados no âmbito estatal para se obter uma melhor concepção do cenário mundial da repreensão de empresas por violação a direitos humanos.

\title{
5 EMPRESAS TRANSNACIONAIS E A VIOLAÇÃO DE DIREITOS FUNDAMENTAIS NO TRABALHO ANÁLOGO AO DE ESCRAVO NA INDÚSTRIA TÊXTIL BRASILEIRA
}

Para ter um melhor entendimento do cenário de repreensão de atos de violação de direitos humanos perpetrados por empresas é necessário analisar, além dos instrumentos utilizados no âmbito internacional, também aqueles adotados no âmbito nacional pela demons- 
trada necessidade de os dois âmbitos se complementarem. Assim, como forma de tornar mais precisa a análise passaremos a expor os mecanismos utilizados no Brasil para a repreensão de empresas no caso específico do trabalho escravo na indústria têxtil.

O Brasil é um expoente mundial na indústria têxtil, tendo sido classificado em 2017 como 50 colocado mundial na produção têxtil, faturando US\$ 42 bilhões de dólares em vendas nesse ano segundo a Associação Brasileira da Indústria Têxtil (ABIT, 2018).

Essa indústria, entretanto, se beneficia extensivamente de trabalho análogo ao escravo. Segundo estudo realizado em 2016 pela Global Slavery Index, 45 milhões de pessoas no mundo vivem sob alguma forma de escravidão, observando-se que o Brasil encontra-se na 51a posição do ranking, com cerca de $0,08 \%$ da sua população vivendo em condições de trabalho análogo ao de escravo, ou seja, cerca de 369.000 pessoas, e o grande responsável por essa estatística no Brasil é o setor têxtil (GLOBAL SLAVERY INDEX, 2018).

$\mathrm{Na}$ legislação brasileira há previsões específicas vedando o trabalho escravo. A Constituição Federal estabelece no artigo 1, III, o princípio da dignidade humana como um dos seus valores fundamentais; também no artigo 5 , III, há a previsão de que ninguém deverá ser submetido a tratamento degradante, e de forma específica no Código Penal encontra-se a tipificação da conduta de condição análoga à de escravo no artigo 149, com pena de reclusão de dois a oito anos, multa, além de pena por violência.

E de acordo com a análise da doutrina e jurisprudência nacional, para a aplicação da legislação mencionada:

Se enquadrando no conceito de trabalho em condição análoga à de escravo os trabalhos forçados; as jornadas exaustivas; os trabalhos em condições degradantes; as restrições de locomoção em razão de dívida contraída com o empregador ou preposto; o cerceamento do uso de qualquer meio de transporte para manter o trabalhador no local de trabalho; a vigilância ostensiva no local de trabalho e a retenção de documentos ou objetos pessoais do trabalhador para mantê-lo no local de trabalho (NOGUEIRA, 2015, p. 251).

Assim, tendo em vista a gravidade dessa situação, o Brasil vem tomando uma série de medidas para erradicar essa situação, e "em certa medida, o país se tornou referência mundial a partir de fiscalizações realizadas que resultaram no resgate de milhares de trabalhadores em condições análogas à de escravo" (KALIL, 2015, p. 16).

Como exemplo de casos marcantes envolvendo a punição aplicada no âmbito nacional a empresas pelo uso do trabalho análogo ao escravo na indústria têxtil estão os casos Zara Brasil e M. Officer.

\subsection{Caso Zara Brasil}

No caso Zara, em junho de 2011 fiscais encontraram ao todo cerca de 50 trabalhadores submetidos a trabalho análogo ao de escravo produzindo roupas para a marca Zara, que pertence ao grupo espanhol Inditex. Nos termos do relatório produzido pela Repórter Brasil e pela Somo, que acompanharam a visita in loco dos inspetores:

As oficinas em que os funcionários trabalhavam e residiam eram ambientes extremamente degradantes. (...) As janelas eram cobertas com tecidos escuros e os ambientes internos sujos, abafados, apertados e com fiação elétrica irregular. Ademais, filhos menores dos trabalhadores transitavam livremente pelo local de trabalho, entre máquinas de costura sem segurança nenhuma (REPÓRTER BRASIL; SOMO, 2015). 
Em consequência disso, a Zara Brasil firmou em 2011 um Termo de Ajustamento de Conduta (TAC) com o Ministério Público do Trabalho (MPT) que previa o pagamento de 3,5 milhões de reais pela empresa para fins de investimentos sociais, além de uma série de obrigações que deveriam ser seguidas pela empresa (MPT; TEM, 2011).

Tal medida foi considerada de extrema importância para o combate a violações aos direitos humanos por empresas (TEIXEIRA, 2018), uma vez que responsabilizou uma grande organização transnacional por atos que ocorreram em sua cadeia de produção, e apesar de que nesse acordo a Zara Brasil não ter sido obrigada a assumir de forma expressa a responsabilidade pela exploração do trabalho análogo ao escravo do qual se beneficiava, o ato de responsabilização por meio do TAC já foi um grande avanço nessa matéria.

Foi descoberto em 2017, no entanto, que a empresa descumpriu com o acordo ao não cumprir de forma efetiva os termos delimitados no TAC, ao apenas transferir a sua produção para outras localidades e não efetuar a melhoria efetiva das formas de trabalho em sua linha de produção. Em decorrência disso a empresa arcou com uma multa de 5 milhões de reais em investimentos sociais, além de ser firmado um novo TAC entre MPT e a Zara Brasil que ampliou a responsabilidade da empresa (MPT, 2017b).

Apesar da importância da celebração do TAC e do reforço que esse ato e a aplicação de multa têm sobre a seriedade do combate realizado pelo MPT e pelo MPE ao trabalho análogo ao de escravo, o descumprimento do primeiro acordo pela empresa e o valor da multa aplicada trazem algumas ressalvas, conforme exposto:

Considerando as circunstâncias fáticas e jurídicas de violações de direitos humanos, as medidas tomadas contribuíram de forma ainda insatisfatória para a solução das violações de direitos humanos na cadeia produtiva da empresa, considerando tanto os direitos difusos e coletivos previstos no ordenamento brasileiro, quanto os parâmetros internacionais da OIT ou dos Princípios Orientadores da ONU (TEIXEIRA, 2018).

Dessa forma, apesar da importância das medidas tomadas ainda seria considerado necessário que seja adotada uma repreensão mais adequada para essas práticas e, principalmente, que a empresa assuma de forma expressa a responsabilidade pelo ato de violação de direitos humanos do qual se beneficiava.

\subsection{Caso M. Officer}

Já no caso envolvendo a empresa M. Officer, foram encontrados trabalhadores em condições análogas às de escravos por meio de investigações ocorridas em 2013 e 2014, que expôs trabalhadores bolivianos trabalhando em local precário, sem divisão clara entre o local de moradia e o local de trabalho, sendo obrigados a trabalhar de segunda à sexta-feira das 7 horas às 22 horas e nos sábados das 7 horas às 12 horas, segundo relatórios do Repórter Brasil (2016).

Em consequência das irregularidades encontradas e da recusa da empresa em firmar um TAC, foi proposta uma Ação Civil Pública pelo MPT e lavrados 25 autos de infração contra a M5 Indústria e Comércio Ltda., dona da marca M. Officer.

O MPT requereu na ação que fosse declarada a responsabilidade solidária da empresa pelas irregularidades sociais e trabalhistas ocorridas em sua cadeia produtiva, que fosse de- 
terminado que a ré, após o trânsito em julgado da ação, mantivesse a sua cadeia produtiva em consonância com a legislação brasileira, e a condenação da ré ao pagamento por danos morais coletivos além de indenização por dumping social (MPT, 2017a).

A empresa foi condenada solidariamente a pagar 6 milhões de reais por trabalho análogo ao de escravo, dos quais 4 milhões por danos morais coletivos e 2 milhões por dumping social, além de se comprometer a manter sua cadeia produtiva em consonância com a legislação brasileira, devendo para isso cumprir com sete obrigações propostas pelo MPT, tendo como pena pelo descumprimento o pagamento de 500 mil reais por obrigação e 50 mil reais por trabalhador afetado, além da possibilidade de proibição de registro de ICMS desta empresa no Estado de São Paulo por 10 anos, o que impede a sua atividade no Estado de São Paulo durante igual período (BRASIL, 2017).

Nesse caso a ação civil pública interposta pelo MPT é fundamental para o combate à prática do trabalho escravo, visto que aplicou o reconhecimento judicial da responsabilização da empresa por violações de direitos humanos cometidas em sua cadeia de produção.

\subsection{Análise dos Instrumentos Nacionais de Responsabilização de Empresas por Violação de Direitos}

Assim, com o estudo dos dois casos apresentados, Zara e M. Officer, é possível concluir que o sistema de Justiça brasileiro possibilita a responsabilização de empresas por transgressão de direitos humanos identificados em sua cadeia produtiva, podendo se identificar três principais mecanismos utilizados pelo Brasil para responsabilizar empresas no caso específico do trabalho análogo ao de escravo.

O primeiro instrumento que pode ser identificado é o TAC, como foi firmado entre o MPT e a Zara Brasil, que promoveu uma série de melhorias nesta empresa desde que foi celebrado, segundo relato do Repórter Brasil e da Somo (2015). O ponto negativo desta medida, entretanto, está no fato de que a empresa não assumiu de forma expressa a responsabilidade pelas violações praticadas e no descumprimento de uma das obrigações estabelecidas, além da dificuldade em fiscalizar de forma adequada o cumprimento do acordo.

O segundo instrumento de responsabilização que pode ser adotado é a ação civil pública, conforme foi proposta pelo MPT no caso contra a M. Officer, que também trouxe resultados positivos ao ter uma sentença procedente reconhecendo a responsabilidade pela cadeia de produção e a obrigação de pagar uma quantia significativa de multa e indenização. O ponto negativo dessa medida, contudo, está na demora do sistema Judiciário brasileiro, que no caso exemplificado demorou cerca de cinco anos para ser julgado, o que é perigoso em casos que envolvem violações tão graves.

E o terceiro instrumento utilizado é a chamada "lista suja" publicada periodicamente pelo MTE, na qual consta o nome de todas as empresas que usam formas de trabalho análogas às de escravo, seja de forma direta ou que se beneficiam dessa prática em sua cadeia produtiva, tendo sido as duas empresas citadas como exemplo inseridas nesse sistema, constituindo esta "uma das medidas administrativas mais bem-sucedidas no combate ao trabalho em condições análogas à escravidão" (TEIXEIRA, 2018, p. 66).

Assim, em decorrência da análise dos casos expostos há, no Brasil, instrumentos eficientes de responsabilização de empresas por violações a direitos humanos, contudo estes 
instrumentos ainda precisam de aperfeiçoamento como em relação a fatores como o valor das multas aplicadas e a fiscalização adequada dos compromissos firmados pelas empresas, mas já mostram um grande avanço nesta temática, também sendo uma forma de concretizar os princípios orientadores da ONU.

\section{CONCLUSÃO}

A partir do entendimento dos diversos estudos expostos provenientes do âmbito econômico, jurídico e psicológico, foi possível chegar a uma resposta para o questionamento inicialmente proposto: indicar quais os meios existentes para minorar e/ou eliminar as violações de direitos humanos pelo setor da indústria têxtil transnacional. Assim, por meio do trabalho realizado elencamos os instrumentos de responsabilização identificados nos casos analisados e concluímos que para que se alcance resultados satisfatórios de proteção aos direitos humanos violados por empresas a abordagem mais adequada é a manutenção do sistema de responsabilização atualmente adotado, investindo no seu aprimoramento.

Desse modo, entendemos que no âmbito internacional deve-se prezar pela difusão e fiscalização de normas de soft law, como os princípios "proteger, respeitar e reparar" criados por John Ruggie, para que empresas internalizem o respeito às normas sociais, principalmente de proteção aos direitos humanos, como vem acontecendo. Nesse sentido expõem diversos autores, como Leandro Zanitelli, Joshua D. Margolis e Min-Doung P. Lee, os quais destacam que há uma tendência de dedicação por parte das empresas para alcançar fins socialmente estimados, como pode ser verificado em estudos empíricos, conforme exposto ao longo do artigo.

Nesse viés, para que se alcance um resultado adequado de proteção aos direitos humanos e para que ao mesmo tempo haja uma prevenção de sua violação por empresas, deve-se investir no âmbito internacional no aprimoramento das normas de soft law já empregadas, como também na criação de novas normas nesta vertente, devendo este sistema internacional ser complementado pela estrutura estatal de punibilidade de atos de transgressão de direitos humanos praticados por empresas.

Assim, é necessário também aprimorar os meios estatais de repreensão dessas práticas, como foi possível perceber a partir do estudo das punições aplicadas pelo Estado brasileiro na repreensão de utilização de trabalhos análogos ao escravo na indústria têxtil.

Os resultados expostos demonstraram que existem instrumentos para o Estado punir de forma eficiente empresas por violação aos direitos humanos, inclusive responsabilizando-as por ilicitudes praticadas em toda a sua cadeia produtiva. Foi possível identificar três principais instrumentos aplicados pelo Estado no caso de punibilidade de empresas transnacionais da indústria têxtil: a utilização do TAC; da Ação Civil Pública e da Lista Suja.

Apesar, no entanto, dos instrumentos aplicados pelo Estado brasileiro apresentarem bons resultados, ainda há várias falhas que devem ser corrigidas. Por exemplo, a fiscalização dos acordos firmados deve ser adequada e contínua, e a ausência da exigência que na realização do TAC a empresa assuma de forma expressa a responsabilidade pelos atos de violação aos direitos humanos dos quais se beneficiava. 
Em decorrência do exposto pode-se afirmar que há instrumentos internacionais e estatais eficientes de responsabilização de empresas por violações aos direitos humanos, e que deve haver uma harmonia/complementaridade entre estes dois âmbitos, forma mais adequada e efetiva, na atualidade, para realizar a prevenção e reparação de violação aos direitos humanos por atos praticados por empresas.

\section{REFERÊNCIAS}

ABIT. Associação Brasileira da Indústria Têxtil e de Confecção. Dados estatísticos. Disponível em: http://www. abit.org.br/. Acesso em: 22 out. 2018.

BECKER, Gary S. Crime and punishment: An economic approach. Journal of Political Economy, v. 76, n. 2, Mar.Abr., p. 169-217, 1968. p. 176. Disponível em: http://webarchiv.ethz.ch/soms/sociology_course/Lecture6/becker1968.pdf. Acesso em: 17 set. 2018.

BECKER, Gary S. Crime and punishment: An economic approach. National Bureau of Economic Resarch, 1974, p. 1-54. Disponível em: http://www.nber.org/chapters/c3625.pdf. Acesso em: 17 set. 2018.

BURWELL v. HOBBY LOBBY STORES, INC., Decision, No. 13-354, 723 F. 3d 1114, affirmed; No. 13-356, 724 F. $3 d$ 377, reversed and remanded. 2014. Disponível em: https://www.law.cornell.edu/supremecourt/text/13-354. Acesso em: 16 out. 2018.

BRASIL. Tribunal Regional do Trabalho da 2a Região. Recurso ordinário n. 0001779- 55.2014.5.02.0054. Recorrente: M5 Indústria e Comércio Ltda. Recorrido: MPT. Relator: Des. Salvador Franco de Lima Laurino. Disponível em: https://aplicacoes8.trtsp.jus.br/sis/acordaoTurma/index/acordao/processo/20140054292/d\%20ata/20171107/ numero/20170683502. Acesso em: 24 set. 2018.

BRASIL. Tribunal Regional do Trabalho da 2a Região. Recurso ordinário no 00017795520145020054 . Recorrente: M5 Indústria e Comércio. Recorrido: União. Relator: Des. Ricardo Artur Costa e Trigueiros. 2017a. Disponível em: http://aplicacoes8.trtsp.jus.br/sis/acordaoTurma/index/acordao/processo/20140054292/d ata/20171107/ numero/20170683502. Acesso em: 24 set. 2018.

BRASIL. Tribunal Regional do Trabalho da 2a Região. Recurso ordinário no 00016629120125020003 . Recorrente: Zara Brasil Ltda. Recorrido: União. Relator: Des. Ricardo Artur Costa e Trigueiros. 2017b. Disponível em: http:// aplicacoes8.trtsp.jus.br/sis/acordaoTurma/index/acordao/processo/20140054292/d ata/20171107/numero/20170683502. Acesso em: 24 set. 2018.

BRITO, Laura Souza e Lima. Liberdade e direitos humanos: fundamentação jusfilosófica de sua universalidade. São Paulo: Saraiva, 2013.

CANOTILHO, José Joaquim Gomes. Direito constitucional e teoria da Constituição. 5. ed. Coimbra: Almedina, 2002.

COMPARATO, Fabio Konder. Fundamento dos direitos humanos. In: MARCílIO, Maria Luiza; RUSSOLI, Lafaiete (coord.). Cultura dos direitos humanos. São Paulo: LTr, 1998. p. 74.

COOTER, Robert. Expressive Law and Economics. 1998. Disponível em: https://scholarship.law.berkeley.edu/cgi/ viewcontent.cgi?article $=1623 \&$ context=facpubs

DIAS, Júnior César. $O$ trabalho infantil nos principais grupamentos de atividades econômicas do Brasil. Brasília: FNPETI. 2016. Disponível em: http: // www.tst.jus.br/documents /2237892/0/estudo/2802c7cc-36a1-c216-cfca328 630c73 119. Acesso em: 17 set. 2018.

FEHR, E.; GÄCHTER, S. Altruistic punishment in humans. Nature. 2002. Disponível em: https://www.researchgate. net/publication/11552998_Altruistic_Punishment_in_Humans. Acesso em: 14 abr. 2019.

FISCHBACHER, U. et al. Third-party punishment and social norms. 2004. Disponivel em: https://www.econ.uzh. ch/dam/jcr:fffffff-9758-127f-0000-00004797af07/iewwp106.pdf. Acesso em: 16 abr. 2019.

FORTUNATO, Sarita A. de Oliveira. O trabalho infantil e as políticas públicas para sua erradicação no Brasil: o pensar sobre a infância e a educação. 2016. Tese (Doutorado) - Universidade Tuiuti do Paraná, Programa de Pós-Graduação em Educação da Faculdade de Ciências Humanas, Letras e Artes, Curitiba, 2016.

GALBIATI, R.; SCHLAG, K. H.; VAN DER WEELE, J. J. Can sanctions induce pessimism? An experiment. 2009. Disponível em: http://papers.ssrn.com/sol3/papers. cfm? abstract_id =1428291. Acesso em: 17 set. 2018. 
GLOBAL JUSTICE NOW. Reining in Corporations. Disponível em: https://www.globaljustice.org.uk//reining-corporations. Acesso em: 7 set. 2018.

GLOBAL SLAVERY INDEX. Country Studies: Brazil. Disponível em: https://www.globalslaveryindex.org/2018/findings/country-studies/brazil/. Acesso em: 23 set. 2018.

JOSEPH, Sarah. Corporations and transnational human rights litigation. Oxford: Hart Publishing, 2004.

KALIL, Renan Bernardi; RIBEIRO, Thiago Gurjão Alves Ribeiro. Trabalho escravo contemporâneo e proteção social. In: Revista Direitos, Trabalho e Política Social, Cuiabá: UFMT, v. 1, n. 1, 2015.

KELL, G. The Global Compact: Selected experiences and reflections. Journal of Business Ethics, v. 59, p. 73.

KNOX, J. H. Horizontal human rights law. 2008. Disponível em: https://wakespace.lib.wfu.edu/bitstream/handle/10339/26074/Knox\%2OHorizontal\%20Human\%20Rights\%20Law.pdf. Acesso em: 16 abr. 2019.

LEE, M. D. P. A review of the theories of corporate social responsibility: Its evolutionary path and the road ahead. 2008. Disponivel em: http://57ef850e78feaed47e42-3eada556f2c82b951c467be415f62411.r9.cf2.rackcdn.com/ Min-2008-ReviewOfTheories.pdf. Acesso em: 14 abr. 2019.

LESSA, Rafaela Ribeiro Zauli et al. A ONU e a responsabilidade internacional de empresas por transgressão aos direitos humanos. RIDH - Revista Interdisciplinar de Direitos Humanos, Unesp, v. 5, n. 2, p. 261-274, jul./dez. 2017.

LESSA, R. R. Z.; REIS, D. M. Submissão das corporações a sanções internacionais e meios não estatais de reparação: possíveis soluções à ineficácia social do Direito ao Trabalho Decente. Anuário Brasileiro de Direito Internacional, v. 2, p. 89-113, 2015.

MARGOLIS, Joshua D.; ELFENBEIN, Hillary A.; WALSH, James P. Does it pay to be good? A meta-analysis and redirection of research on the relationship between corporate social and financial performance. Harvard University: Business School. 2007. Disponível em: https://sites.hks.harvard.edu/m-rcbg/papers/seminars/margolis_november_07.pdf. Acesso em: 16 set. 2018.

MPT. Ministério Público do Trabalho. Condenada por trabalho escravo, M .Officer pode ser proibida de vender em SP por 10 anos. 2017a. Disponível em: http://portal.mpt.mp.br/wps/portal/portal_mpt/mpt/sala-imprensa/ mpt-noticias/. Acesso em: 23 set. 2018.

MPT; TEM. Ministério Público do Trabalho; Ministério do Trabalho e Emprego. Termo de ajuste de conduta - Inquérito Civil n. 000393.2011.02.002/2. São Paulo, 2011.

MPT. Ministério Público do Trabalho. Termo de Ajuste de Conduta entre MPT e Zara amplia responsabilidade em cadeia produtiva da marca. 2017b. Disponível em: http://www.prt2.mpt.mp.br/453-termo-de-ajuste-de-condita-entre-mpt-e-zara-amplia responsabilidade-em-cadeiaprodutiva-da-marca. Acesso em: 23 set. 2018.

NOGUEIRA, Christiane V. et al. Recentes avanços legislativos no combate à escravidão. In: Estudos Aprofundados $M P T$, v. 1. Salvador: JusPODIVM, 2015. p. 251.

ONU. Organização das Nações Unidas. Declaração Universal dos Direitos Humanos. Paris, 1948.

OSHIONEBO, Evaristus. The U.N. Global Compact and accountability of transnational corporations: Separating myth from realities. Florida Journal of International Law, Florida, v. 19, n. 1, p. 2-30, Apr. 2007.

REPÓRTER BRASIL; SOMO. Da responsabilização moral à responsabilização jurídica? As condições de escravidão moderna na cadeia global de suprimentos da indústria do vestuário e a necessidade de fortalecer os marcos regulatórios: o caso da Inditex-Zara no Brasil. São Paulo: Repórter Brasil \& SOMO, 2015.

REPÓRTER BRASIL. M. Officer é condenada a pagar $\$ \$ 6$ mi por casos de trabalho análogo ao de escravo. Website. São Paulo: Repórter Brasil, 2016. Disponível em: http://reporterbrasil.org.br/2016/11/m-officer-e-condenada-a-pagar-r-6-mi-por-casosde-trabalho-analogo-ao-de-escravo/. Acesso em: 23 set. 2018.

RUGGIE, J. G. Global_Governance.net: The Global Compact as learning network. Global Governance. 2001. Disponível em: https://www.jstor.org/stable/27800311?read-now=1\&seq=4\#page_scan_tab_contents. Acesso em: 16 abr. 2019.

TEIXEIRA, Bárbara Bittar. Direitos humanos e empresa: a responsabilidade por exploração de trabalhadores em condições análogas à de escravo nas cadeias produtivas da indústria têxtil. 2018. Dissertação (Mestrado) - Escola de Direito de São Paulo da Fundação Getulio Vargas, 2018.

UTTING, Peter. Corporate responsibility and the movement of business. 2005. Disponivel em: http://unrisd.org/80256B3C005BCCF9/(httpAuxPages)/67924234EC32460FC125705A002F5FC3/\$file/MovBus.pdf. Acesso em: 16 abr. 2019. 
UNITED NATIONS. Protect, Respect and Remedy: a Framework for Business and Human Rights: Report of the Special Representative of the Secretary-General on the issue of human rights and transnational corporations and other business enterprises, John Ruggie. Doc. ONU A/HRC/8/5. Disponível em: https://documents-dds-ny. un.org/doc/UNDOC/GEN/G08/128/61/pdf/G0812861.pdf?OpenElement. Acesso em: 7 set. 2018.

UNITED NATIONS GLOBAL COMPACT. The ten principles. Disponível em: https://www.unglobalcompact.org/what-is-gc/mission/principles. Acesso em: 16 set. 2018.

WINTER, Luís Alexandre Carta. O Mercosul e o Sistema Presidencialista. 2008. Tese (Doutorado em Integração da América Latina) - Integração da América Latina Universidade de São Paulo, São Paulo, 2008. DOI: 10.11606/T.84.2008.tde-10112009-144912. Acesso em: 15 out. 2018.

WINKLER, Adam. We the Corporations: how american bussines won their civil rights. 1. ed. New York: Liveright Publishing Corporation, 2018.

ZANITELLI, Leandro Martins. Corporações e direitos humanos: o debate entre voluntaristas e obrigacionistas e o efeito solapador das sanções. Sur - Revista Internacional de Direitos Humanos. 2011. Disponível em: https://sur. conectas.org/corporacoes-e-direitos-humanos/. Acesso em: 16 abr. 2019. 